\title{
Supply Chain Decision-Making Based on Warehouse Receipt Pledge and Risk Consideration under Twice Ordering Mode
}

\author{
Liang Wang $\mathbb{D}$, Tingjia Xu $\mathbb{D}$, and Shi Zhu \\ School of Economics and Business Administration, Xian University of Technology, Xian 710048, China \\ Correspondence should be addressed to Liang Wang; wangliang@xaut.edu.cn
}

Received 22 April 2018; Revised 1 July 2018; Accepted 8 July 2018; Published 30 July 2018

Academic Editor: Przemyslaw Ignaciuk

Copyright (C) 2018 Liang Wang et al. This is an open access article distributed under the Creative Commons Attribution License, which permits unrestricted use, distribution, and reproduction in any medium, provided the original work is properly cited.

\begin{abstract}
This paper studies supply chain decisions making between the retailer, supplier, and bank based on warehouse receipt pledge and risk consideration under twice ordering mode. The decentralized supply chain and centralized supply chain are divided by whether the supplier provides repurchase guarantees and whether the retailer offers revenue sharing. We develop a Stackelberg game model to analyze the influential mechanism among various actors and use the method of downside risk control to discuss the bank's expected loss and the optimal loan pledge ratio. We carry out a simulation analysis, and the result is shown as follows: (i) either for decentralized or centralized supply chain, the retailer's optimal order quantity and the optimal proportion that the number of goods pledged by the retailer's twice ordering accounts for the number of first-ordering goods are all unique; (ii) the bank's loan pledge ratio is a monotonically increasing function of disposal value of the unit remaining commodity; (iii) for centralized supply chain, the bank's loan pledge ratio is the monotonically increasing function of repurchase ratio and wholesale price provided by the supplier, respectively; (iv) in the decentralized supply chain, the supplier's return mainly comes from the wholesale revenue and is positively related to the wholesale volume and wholesale price; in the centralized supply chain, the supplier's return is mainly from the retailer's revenue sharing.
\end{abstract}

\section{Introduction}

Warehouse receipt pledge financing is one of the important ways to solve the financing difficulty of small and mediumsized enterprises (SME). The pledge of warehouse receipts cannot only solve the problem of liquidity shortage in SMEs but also guarantee loan for the bank.

Many previous studies have concerned about supply chain financing. Buzacott and Zhang [1] made the first attempt to incorporate the asset financing into production decisions. By analyzing the relationship between production decisions and capital structure, Birge and Xu (2004) explored the impact of capital constraints on production decisions of the firm in a stochastic demand market; they further constructed a Newsboy model to study the issue of capital constraints and incentive management under the optimal production decision. Subsequently, Dada [2] used the same method, which was to study the financing inventory management strategy by adding capital constraints on the basis of the classic Newsboy model. Fellenz and Augustenborg [3] studied the dynamic models and practices of financial flows in global supply networks. Based on data collected from suppliers, solutions to improve the challenges of supply chain financing were identified and discussed. This research is of particular significance in dealing with the devastation brought by the global credit crisis to global financial system. Caldentey [4] studied retailers with financial constraints in a typical supply chain and thought of ways to use market financing to ease the retailer's financial constraints. Furthermore, Lai, Debo, and Sycara [5] studied the impact of capital constraints on the Stackelberg game and the efficiency of various models in supply chain finance. Under capital constraints, suppliers prefer the booking model. However, only the hybrid model can make the entire supply chain system optimal. With further development of research on supply chain finance, scholars also studied it more deeply and meticulously. Zheng and $\mathrm{Hu}$ [6] elaborated on the benefits of supply chain and formulated an equilibrium pricing mechanism through the 
model establishment and game analyzing, thus ensuring the maximum benefit of all participants. Bi and Dong [7] built a credit risk assessment system for supply chain finance, which contributes to reducing the risk and enhancing the security of supply chain finance. Combining trapezoidal fuzzy numbers with the entropy weight theory, they comprehensively evaluated various indicators to improve the accuracy of evaluation. This evaluation method is relatively scientific, which overcomes the disadvantages of triangular fuzzy numbers and reduces the judgment error of credit risk in supply chain finance. Under conditions of uncertain demand and consumption, Liu and $\mathrm{He}$ [8] studied the optimal order decision in the supply chain under uncertain demand and uncertain consumption and analyzed supply chain coordination under different strategies. They found that under repurchase strategy, the supply chain can be coordinated, whereas the wholesale price strategy cannot coordinate the supply chain. Wuttke and Blome [9] found that the initial payment terms and purchase volume strongly affect the optimal timing of introduction and the optimal payment term extensions of supply chain finance. Zhang and Hong [10] established a decentralized supply chain between a supplier and a manufacturer. It is believed that the investment and pricing decisions in the decentralized supply chain are different from that of centralized supply chain, so they set a coordination mechanism. Hofmann et al. [11] took a modeling analysis to the game relationships among consumers, suppliers, and banks in supply chain finance. The study concluded that as a mutually beneficial and win-win model, supply chain finance also faces barriers to accounting standards and the bank's supervision. Fang et al. [12] analyzed the optimal operation and financing strategies of supply chain when the retailer raises money through bank loans or equity financing. The result shows that retailer's capital level can significantly influence supply chain decisions and the retailer's financing option. Pellegrino et al. [13] argued that two Supply Chain Risk Management (SCRM) strategies, namely, commodity substitution and supplier conversion, are important factors in reducing Commodity Price Volatility (CPV) in supply chain finance. Through using a Real Option Valuation (ROV) model and taking a simulation analysis, they found that the flexibility of sunk cost and the purchasing volume are all key factors that should be considered in the process of operating these two strategies.

In terms of warehouse receipt pledge business in supply chain finance, scholars also carried out some related research, but most of them are related to risks. Jokivuolle [14] proposed a risk-mortgage model linking the value of collateral with the possibility of default. The model is a function of the pledge; it can be mainly used to study the expected loss of given default. Cossin [15] derived a general framework for risk control analysis of repurchase transactions or repurchase collaterals. With the assumption of the exogenous default, the discount rate for collateral was derived and it should be consistent with the bank's risk appetite. In recent years, many domestic scholars studied a lot in the risk control of warehouse receipt pledge. Through analyzing the status quo and existing problems of the warehouse receipt pledge in China, Wang and Yin [16] put forward some strategies for the pledge business in SMEs, which contributed to reducing the financing risk for SMEs. Liu [17] thought that warehouse receipt pledge is a new type of profit-making method for logistics enterprises. He introduced the main business model, risks, and corresponding preventive measures of warehouse receipts and analyzed three new financing models: confirmation warehouse, the right to pledge commodity, and financing warehouse. Hui and Zhen [18] discussed the pledge ratio, the core indicator of risk control in warehouse receipt pledge. With a single-cycle Newsboy model, they investigated the retailers' ordering decisions. On this basis, dynamic game theory and VaR method were used to study the decisions of pledge ratio in two cases: the pursuit of profit maximization and weighing risks and benefits. Finally, looking for different goals, they derived the model analysis and the decision of numerical simulation optimization. Liu [19] further explored the warehouse receipt pledge financing, the risk, and corresponding risk management strategies, especially risk management strategies of third-party logistics companies. Tang, Chu, and Li [20] applied Risk Value Theory to study the risk of warehouse receipts and used VaR model to select the pledge loan business of financial institutions. They provided an effective set of method for banks. Reddy et al. [21] took an empirical research on the pledge financing of warehouse receipts in Hyderabad-Karnataka region and concluded that this financing model is of significance among farming community, which also is effective in reducing the risk of selling agricultural produce in lower price. Liu [22] found that under the static pledge mode, logistics enterprises face great risks, especially the risk brought by price fluctuations. From the perspective of warehouse space changing, Luo et al. [23] constructed storage space allocation models for customers under dynamic and static pledge demand from the perspective of supply chain and used the robust optimization method to optimize the results. Research shows that the reduction in pledge costs can increase the utilization efficiency of storage space and the returns of participants. Wang et al. [24] used Petri net to discuss the business process and risks of nonstandard warehouse receipt pledge credit; they deduced that this method can optimize the business process and is conducive to the product innovation of supply chain.

As mentioned above, most previous studies on warehouse receipt pledge were conducted from the perspectives of suppliers and retailers, without considering the mode of twice ordering by warehouse receipts pledge, the return of banks and risk control issues. In view of this, this paper studies the decision-making process between a retailer, a supplier, and a bank when warehouse receipts are pledged under twice ordering mode. The results derived from this study make several contributions. First, the decentralized decisionmaking and centralized decision-making are divided by whether the supplier provides repurchase guarantees and whether the retailer adopts revenue sharing; hence, the influential mechanism for participants in the supply chain is analyzed through mathematical modeling. Second, for the two situations of decentralized and centralized decisionmaking, the optimal proportion of retailer's pledged commodity is deduced through mathematical derivation. Third, the downside risk control method is used to analyze the 
bank's expected loss and the optimal loan pledge ratio. Fourth, the differences of supplier's profit model are discussed through simulation for decentralized decision-making and centralized decision-making.

This paper proceeds as follows. Section 2 proposes the basic assumptions of the model and defines the symbols for each variable. Sections 3 and 4 analyze the decision process for the decentralized supply chain and the centralized supply chain, respectively, by establishing the expected return functions and decision-making models for participants. Section 5 simulates the supply chain of the two decision types. Section 6 takes expansion studies. And we conclude the paper in Section 7 with closing remarks.

\section{Preliminaries}

For simplicity, we assume that (i) there are a bank, a retailer, and a supplier in the market, and they have symmetrical information in the decision-making process; (ii) if the retailers are short of funds, they can make use of the valid commodity warehouse receipts issued by the logistics enterprise to carry out the warehouse receipt pledged financing; (iii) the bank allows the retailers to sell the goods pledge for the warehouse receipt, but the retailers should immediately offset the bank's loan if they receive funds after selling the pledge; (iv) the retailers will not maliciously fail to repay the loan, they will not pay the bank's financing principal and interest only in the case of bankruptcy, and the bank has priority to sell the pledged commodity simultaneously; (v) the retailer is not allowed to postpone payment in the decentralized supply chain; (vi) the market demand $x$ is stochastic, its value is between the first-ordering quantity and the total ordering quantity, and it has a characteristic of increasing failure rate (IFR); that is, the function $f(x) /(1-F(x))$ is an increasing function of $x$; and (vii) the retail price of a commodity remains unchanged.

We use the following symbols to denote each variable in the decentralized supply chain, whereas for the centralized supply chain, the subscript of the variable is marked with $\mathrm{c}$.

Let $B$ be the initial amount of fund of the retailer; $c$ is the production cost of the unit commodity; $p$ is the retail price of the unit commodity; $w$ is the wholesale price of the unit commodity; $r_{b}$ is the interest rate charged by the bank at the time of pledge financing; $r_{f}$ is the risk-free interest rate based on the one-year fixed deposit rate; $\beta$ is the pledge ratio required by the bank when providing the loan, $0<\beta \leq 1 ; x$ is the market stochastic demand for commodities, we assume that its probability density function is $f(\cdot)$ and the probability distribution function is $F(\cdot) ; \varphi_{r}$ indicates the probability of a retailer defaulting; $D$ is the retailer's total financing amount; $\gamma$ is the proportion that the number of goods pledged by the retailer's twice ordering accounts for the number of firstordering goods; $Q$ is the retailer's total order quantity, $Q=$ $Q_{1}+Q_{2}$, where $Q_{1}$ is the retailer's first-ordering quantity and $Q_{2}$ is the twice ordering quantity; $s$ is the unit deposit value of the remaining commodities pledged at bank after the bankruptcy of retailer; $t$ is the repurchase rate promised by the supplier; $\lambda$ is the revenue sharing coefficient between retailer and supplier.

\section{Research on Decision-Making of Decentralized Supply Chain under Conditions of Supplier's Nonrepurchase and Twice Ordering Mode}

For decentralized supply chain, the supplier does not offer a repurchase guarantee to the retailer, and there is no revenue sharing between them. The retailer can only passively accept decisions made by the bank because it is the leader in the Stackelberg game. Specifically, the supplier first gives $w$, the wholesale price of the unit commodity. If the retailer is underfunded, it will make the first ordering based on the wholesale price $w$, and the order quantity is $Q_{1}$. Hence, according to the value of commodities ordered for the first time, the pledge ratio $\beta$, and the estimation of market demand $x$, the retailer will determine the proportion $\gamma$,which is the number of goods pledged in twice ordering accounts for the number of first-ordering goods. After reaching warehouse receipt pledge loan agreement with the bank, the retailer meets the market demand through twice ordering mode. Therefore, based on the previous variable assumption, the retailer's first-ordering quantity is

$$
Q_{1}=\frac{B}{w}
$$

The quantity of twice ordering is

$$
Q_{2}=\frac{\beta p \gamma Q_{1}}{w}
$$

The total ordering quantity of the two times is

$$
Q=Q_{1}+Q_{2}=\frac{(B w+\beta \gamma p B)}{w^{2}}
$$

And the total amount of the retailer's pledge loan is

$$
D=\beta p \gamma Q_{1}=\beta p \gamma \frac{B}{w}
$$

From (3) and (4), we can deduce that the retailer's firstordering quantity is

$$
Q_{1}=\frac{Q w}{(w+\beta p \gamma)}
$$

\subsection{Expected Return Functions of Participants}

3.1.1. The Bank's Expected Return Function. The risk borne by the bank comes from the market risk of product price fluctuations and credit risk of the company's breach of contract. If the sum of the retailer's income $x p$ and the value $(Q-x) s$ of remaining goods pledged in warehouses is greater than the sum of principal and interest of pledged loans, the retailer can pay the principal and interest of loans at this time. In other words, when the pledge loan expires, if

$$
x p+(Q-x) s \geq \beta \gamma Q_{1} p e^{r_{b}}
$$


the market demand $x \geq\left(\gamma Q_{1} \beta p e^{r_{b}}-Q s\right) /(p-s)$, the retailer will repay the bank's principal and interest, and the bank's profit will be

$$
\Pi_{B}=\beta \gamma Q_{1} p\left(e^{r_{b}}-e^{r_{f}}\right)
$$

If the retailer's sales revenue cannot pay off the principal and interest of pledged loan because of insufficient market demand of goods or other factors, it may choose to default. According to the previous assumptions, it can be seen that under the condition of insufficient demand that $x \leq$ $\left(\gamma Q_{1} \beta p e^{r_{b}}-Q s\right) /(p-s)$; if the retailer defaults and goes bankrupt, the bank's expected return will be

$$
\begin{aligned}
E \pi_{B}^{\varphi_{r}}= & p \int_{0}^{\left(\gamma Q_{1} \beta p e^{r_{b}}-\mathrm{Q} s\right) /(p-s)} x f(x) d x \\
& +s \int_{0}^{\left(\gamma \mathrm{Q}_{1} \beta p e^{r_{b}}-\mathrm{Q} s\right) /(p-s)} f(x) d x \\
& -\beta \gamma Q_{1} p e^{r_{f}} F\left(\frac{\gamma Q_{1} \beta p e^{r_{b}}-Q s}{p-s}\right)
\end{aligned}
$$

In addition, because $\varphi_{r}$ is the probability of a retailer defaulting, taking into account the occurrence of the above two conditions, the bank's expected return will be

$$
\begin{aligned}
E \pi_{B}= & \Pi_{B}\left(1-F\left(\frac{\gamma Q_{1} p \beta e^{r_{b}}-Q s}{p-s}\right)\right) \\
& +\left(1-\varphi_{r}\right) \Pi_{B} F\left(\frac{\gamma Q_{1} p \beta e^{r_{b}}-Q s}{p-s}\right)+\varphi_{r} E \pi_{B}^{\varphi_{r}} \\
= & \beta \gamma Q_{1} p\left(e^{r_{b}}-e^{r_{f}}\right) \\
& -\varphi_{r}(p-s) \int_{0}^{\left(\gamma Q_{1} p \beta e^{r_{b}}-Q s\right) /(p-s)} F(x) d x
\end{aligned}
$$

3.1.2. The Retailer's Expected Return Function. The retailer's expected return is also divided into two cases according to whether it is bankrupt or not. For simplicity, we assume that if the retailer goes bankrupt, it cannot pay loan principal and interest, and the pledged item is taken away by the bank at this time, the retailer's expected return function is

$$
\begin{aligned}
E \pi_{r}= & \left(1-\varphi_{r}\right)[p \min (Q, x)-C] \\
& +\varphi_{r} p \int_{0}^{\gamma Q_{1} \beta p e^{r_{b}} / p} F(x) d x
\end{aligned}
$$

In light of (4) and (5), it can be seen that the retailer's total amount of loan is

$$
D=\frac{\beta p w Q}{(w+\beta p)}
$$

According to (3), the retailer's initial funding is

$$
B=\frac{w^{2} Q}{(w+\beta p)}
$$

We can deduce the retailer's expected return is

$$
\begin{aligned}
E \pi_{r}= & \left(1-\varphi_{r}\right)\left[Q(p-w)-\frac{\beta p \gamma B e^{r_{b}}}{w}\right] \\
& +\varphi_{r} p \int_{0}^{Q} F(x) d x
\end{aligned}
$$

3.1.3. The Supplier's Expected Return Function. We assume that the retailer does not delay payment, the wholesale price $w$ is bigger than production cost $c$, that is $w>c$, and other costs are ignored; then the supplier's profit will be directly affected by the retailer's order quantity. In the decentralized supply chain, the supplier does not undertake repurchase; hence, it does not take any risk, even if the retailer goes bankrupt, its financing risk is only borne by the bank. Therefore, according to (3), it is easy to deduced that the supplier's expected return function is

$$
E \pi_{s}=(w-c) Q=\frac{(w-c)(B w+\beta p \gamma B)}{w^{2}}
$$

3.2. Decision-Making Models of Decentralized Supply Chain. In the decentralized supply chain, we only analyze the decision-making behaviors of the retailer and bank. Because the supplier's profit is mainly affected by the retailer's order quantity, so it does not have repurchase promise and revenue sharing.

3.2.1. The Retailer's Decision. Because the order quantity is determined by the retailer unilaterally in decentralized supply chain, hence, the decisions of the bank and supplier will not affect the retailer. The following theorem is for the optimal proportion $\gamma^{*}$, which is the optimal proportion that the number of goods pledged by the retailer's twice ordering accounts for the number of first-ordering goods.

Theorem 1. In the decentralized supply chain, when the supplier does not repurchase, the optimal total quantity by the retailer satisfies $Q^{*}=\left(B w+\beta p \gamma^{*} B\right) / w^{2}$, where the optimal proportion $\gamma^{*}$ is unique, and it satisfies

$$
\begin{aligned}
& \left(1-\varphi_{r}\right)\left[p(1-F(Q))-\frac{\beta p w \gamma e^{r_{b}}}{w+\beta p \gamma}\right] \\
& +\varphi_{r} p \frac{\beta w \gamma e^{r_{b}}}{w+\beta p \gamma} F\left(\frac{\beta Q w \gamma e^{r_{b}}}{w+\beta p \gamma}\right)=0
\end{aligned}
$$

Proof. In light of (5), the total financing amount $D$ is expressed by $Q$; hence, $D=\gamma Q_{1} \beta p e^{r_{b}} / p=\gamma \beta w Q e^{r_{b}} /(w+$ $\beta p \gamma)$; the partial derivative of (13) on $Q$ is

$$
\begin{aligned}
\frac{\partial E \pi_{r}}{\partial Q}= & \left(1-\varphi_{r}\right)\left[p(1-F(Q))-\frac{\beta p w \gamma e^{r_{b}}}{w+\beta p \gamma}\right] \\
& +\varphi_{r} p F\left(\frac{\beta Q w \gamma e^{r_{b}}}{w+\beta p \gamma}\right)\left(\frac{\beta w \gamma e^{r_{b}}}{w+\beta p \gamma}\right)
\end{aligned}
$$


And the second partial derivative of (13) on $Q$ is

$$
\begin{aligned}
& \frac{\partial^{2}\left(E \pi_{r}\right)}{\partial Q^{2}}=\left(1-\varphi_{r}\right)[-p f(Q)]+\varphi_{r} p f\left(\frac{\beta \gamma w Q e^{r_{b}}}{w+\beta p \gamma}\right) \\
& \cdot\left(\frac{\beta \gamma w e^{r_{b}}}{w+\beta p \gamma}\right)^{2}=\left(1-\varphi_{r}\right)(-p)[f(Q) \\
& \left.-\frac{\varphi_{r}}{1-\varphi_{r}} f\left(\frac{\beta \gamma w Q e^{r_{b}}}{w+\beta p \gamma}\right)\left(\frac{\beta \gamma w e^{r_{b}}}{w+\beta p \gamma}\right)^{2}\right]=\left(1-\varphi_{r}\right) \\
& \cdot(-p)[1-F(Q)]\left[\frac{f(Q)}{1-F(Q)}\right. \\
& \left.-\frac{\varphi_{r}}{1-\varphi_{r}}\left(\frac{\beta \gamma w e^{r_{b}}}{w+\beta p \gamma}\right)^{2} \frac{f\left(\beta \gamma w Q e^{r_{b}} /(w+\beta p \gamma)\right)}{1-F(Q)}\right]
\end{aligned}
$$

According to the characteristic of IFR, it can be shown that $f(x) /(1-F(x))$ is an increasing function about $x$, so $\partial^{2}\left(E \pi_{r}\right) / \partial Q^{2}<0$, and $E \pi_{r}$ is a concave function about $Q$ with a unique solution. For the sake of $Q^{*}=\left(B w+\beta p \gamma^{*} B\right) / w^{2}$ and it is unique, $\gamma^{*}$ is also unique which is determined by (16).

3.2.2. The Bank's Decision. We assume that $l$ is the degree of loan loss determined by the bank, $L$ is the maximum loss that the bank is willing to bear, and it is a function of pledge loan $D$. If the bank adopts the downside risk control model $(l, \psi)$ to manage financial risks, then the probability that the loan loss exceeds the control standard is $\psi=P($ Loss $>L)=$ $\varphi_{r} P($ loss $>l)$, and the bank's loan pledge ratio $\beta$ can be obtained by solving

$$
\begin{aligned}
\max \quad E & \pi_{B}(\beta) \\
= & \beta \gamma Q_{1} p\left(e^{r_{b}}-e^{r_{f}}\right) \\
& \quad-\varphi_{r}(p-s) \int_{0}^{\mathrm{Q}\left(\beta p e^{\left.r_{b}-s\right) /(p-s)}\right.} F(x) d x
\end{aligned}
$$

$$
\text { s.t. } \quad P(\text { Loss }>L)=\varphi_{r} p(\text { loss }>l) \leq \psi
$$

In (18), loss $=\beta \gamma Q_{1} p e^{r_{b}}-p \int_{0}^{\left(\gamma \mathrm{Q}_{1} \beta p e^{\left.r_{b}-Q s\right) /(}(p-s)\right.} x f(x) d x-$ $s \int_{0}^{\left(\gamma Q_{1} \beta p e^{r_{b}}-Q s\right) /(p-s)}(Q-x) f(x) d x$ represents the expected loss incurred by the bank during the pledge of loan.

Theorem 2. Under the condition of twice ordering and the supplier's nonrepurchase, if the bank adopts the downside risk control model $(l, \psi)$ to carry out the pledge loan business, the loan pledge ratio $\beta$ for the bank's maximum expected return will be

$$
\begin{aligned}
& \beta \\
& = \begin{cases}\frac{(p-s) F^{-1}\left(\Delta r / \varphi_{r}\right)+Q s}{\gamma Q_{1} p e^{r_{b}}} & \text { if } F\left(\frac{\widehat{\beta} p \gamma Q_{1} \Delta l-Q s}{p-s}\right) \leq \frac{\psi}{\varphi_{r}} \\
\frac{(p-s) F^{-1}\left(\psi / \varphi_{r}\right)+Q s}{\gamma Q_{1} p \Delta l} & \text { if } F\left(\frac{\widehat{\beta} p \gamma Q_{1} \Delta l-Q s}{p-s}\right)>\frac{\psi}{\varphi_{r}}\end{cases}
\end{aligned}
$$

where $\widehat{\beta}=\frac{(p-s) F^{-1}\left(\Delta r / \varphi_{r}\right)+Q s}{\gamma Q_{1} p e^{r_{b}}}, \Delta r=1-e^{r_{f}-r_{b}}, \Delta l=e^{r_{b}}-l$.
Proof. According to (9), the first partial derivative and the second partial derivative of $E \pi_{B}$ on $\beta$ are as follows:

$$
\begin{aligned}
\frac{\partial E \pi_{B}}{\partial \beta}= & \gamma Q_{1} p\left(e^{r_{b}}-e^{r_{f}}\right) \\
& -\varphi_{r} \gamma Q_{1} p e^{r_{b}} F\left(\frac{\gamma Q_{1} \beta p e^{r_{b}}-Q s}{p-s}\right) \\
\frac{\partial^{2}\left(E \pi_{B}\right)}{\partial \beta^{2}}= & -\frac{\varphi_{r} \gamma^{2} Q_{1}^{2} p^{2}\left(e^{r_{b}}\right)^{2}}{p-s} f\left(\frac{\gamma Q_{1} \beta p e^{r_{b}}-Q s}{p-s}\right) \\
< & 0
\end{aligned}
$$

Therefore, the bank's expected return function $E \pi_{B}$ is a concave function of pledge ratio $\beta$. Let $\partial E \pi_{B} / \partial \beta=0$; we can get

$$
F\left(\frac{\gamma Q_{1} \beta p e^{r_{b}}-Q s}{p-s}\right)=\frac{\Delta r}{\varphi_{r}}
$$

At the same time, when the bank's expected return is maximized,

$$
\widehat{\beta}=\frac{(p-s) F^{-1}\left(\Delta r / \varphi_{r}\right)+Q s}{\gamma Q_{1} p e^{r_{b}}}
$$

In light of the constraint of bank's risk control in (18), the probability of loan loss greater than $L$ is $P($ Loss $>L) \leq \psi$; hence, there is

$$
\begin{aligned}
p(\text { Loss }>L)=\varphi_{r} P(\text { loss }>l) \\
\quad=\varphi_{r} P\left(\beta \gamma Q_{1} p e^{r_{b}}-Q s-(p-s) x>l \beta \gamma Q_{1} p\right) \\
\quad=\varphi_{r} P\left(x<\frac{\beta \gamma Q_{1} p \Delta l-Q s}{p-s}\right) \\
\quad=\varphi_{r} F\left(\frac{\beta \gamma Q_{1} p \Delta l-Q s}{p-s}\right)<\psi
\end{aligned}
$$

If $F\left(\left(\widehat{\beta} p \gamma Q_{1} \Delta l-Q s\right) /(p-s)\right) \leq \psi / \varphi_{r}$, and $\beta=\widehat{\beta}$ is the optimal loan pledge rate that can maximize the bank's expected return. If $F\left(\left(\widehat{\beta} p \gamma Q_{1} \Delta l-Q s\right) /(p-s)\right)>\psi / \varphi_{r}$, the maximum value of $\beta$ is the optimal loan pledge rate that achieves the goal of downside risk control. Combined with (23), it shows that $P($ Loss $>L)$ is a monotonically increasing function of $\beta$, while $E \pi_{B}$ is monotonically increasing in interval $[0, \widehat{\beta}]$ from (9). Consequently, the bank's optimal loan pledge ratio is

$$
\beta=\frac{(p-s) F^{-1}\left(\psi / \varphi_{r}\right)+Q s}{\gamma Q_{1} p \Delta l}
$$

Theorem 2 is proved.

We further discuss the relationship between the loan pledge ratio and the value of pledged commodities. There is the following theorem. 
Theorem 3. Under the condition of twice ordering and the supplier's nonrepurchase, loan pledge ratio $\beta$ is a monotonically increasing function of the unit deposit value of the remaining commodities pledged at bank after the bankruptcy of retailer.

Proof. According to (22) and (24), when $F\left(\left(\widehat{\beta} p \gamma Q_{1} \Delta l-\right.\right.$ $Q s) /(p-s)) \leq \psi / \varphi_{r}$, there is $\partial \hat{\beta} / \partial s=\left(Q-F^{-1}\left(\Delta r / \varphi_{r}\right)\right) /$ $\gamma Q_{1} p e^{r_{b}}$, where the value of $F^{-1}\left(\Delta r / \varphi_{r}\right)$ is equal to the minimum market demand that keeps the retailer from going bankrupt. Furthermore, from assumptions in Section 2, we know that $Q>F^{-1}\left(\Delta r / \varphi_{r}\right)$, so $\partial \widehat{\beta} / \partial s>0$. When $F\left(\left(\widehat{\beta} p \gamma Q_{1} \Delta l-Q s\right) /(p-s)\right)>\psi / \varphi_{r}$, there is $\partial \beta / \partial s=(Q-$ $\left.F^{-1}\left(\psi / \varphi_{r}\right)\right) / \gamma Q_{1} p \Delta l$.

Since $F(x)$ is a monotonically increasing function and by (19), it suffices to show that $\left(\widehat{\beta} p \gamma Q_{1} \Delta l-Q s\right) /(p-s)>F^{-1}(\psi /$ $\left.\varphi_{r}\right)$ when $F\left(\left(\widehat{\beta} p \gamma Q_{1} \Delta l-Q s\right) /(p-s)\right)>\psi / \varphi_{r}$. At the moment, $\partial \beta / \partial s=\left(Q-F^{-1}\left(\psi / \varphi_{r}\right)\right) / \gamma Q_{1} p \Delta l>\left(Q-\left(\widehat{\beta} p \gamma Q_{1} \Delta l-Q s\right) /(p-\right.$ $s)) / \gamma Q_{1} p \Delta l>\left(Q-\left(\widehat{\beta} p \gamma Q_{1} e^{r_{b}}-Q s\right) /(p-s)\right) / \gamma Q_{1} p \Delta l$. On the other hand, we can know that $Q>\left(\widehat{\beta} p \gamma Q_{1} e^{r_{b}}-Q s\right) /(p-s)$ from $x \geq\left(\gamma Q_{1} \beta p e^{r_{b}}-Q s\right) /(p-s)$ in Section 3.1.1; hence, $\partial \beta / \partial s>0$ can be proved. The proof is completed.

The above proof process clearly shows that the bank's loan pledge ratio $\beta$ is a monotonically increasing function of the unit deposit value of the remaining commodities pledged at bank after the bankruptcy of retailer.

\section{Research on Decision-Making of Centralized Supply Chain under Conditions of Supplier's Nonrepurchase and Twice Ordering Mode}

In the centralized supply chain, the supplier provides a repurchase guarantee for the retailer, which will reduce the risk of bank's pledged loans, and the bank will adjust the loan pledge ratio $\beta$ or interest rate $r_{b}$. At the same time, both the supplier and retailer can reach a revenue sharing agreement to maximize their return. Moreover, due to the repurchase guarantee and revenue sharing agreement in the centralized supply chain, we regard the retailer and supplier as a benefit community and take their expected returns as a whole.

\subsection{Expected Return Functions of Participants}

4.1.1. The Bank's Expected Return Function. Combined with the research in Section 3.1.1 above, we can also deduce that for the centralized supply chain with retailer's nondefault, market demand $x$ satisfies

$$
x p+(1-t)\left(Q_{c}-x\right) s+t\left(Q_{c}-x\right) w \geq \beta \gamma Q_{c 1} p e^{r_{b}}
$$

where $\Delta s=t w+(1-t) s, t$ is the repurchase ratio, $s$ is the disposal price, and $Q_{c 1}$ is the retailer's first-ordering quantity in the centralized supply chain. That is, when $x \geq$ $\left(\gamma Q_{c 1} \beta p e^{r_{b}}-\Delta s Q_{c}\right) /(p-\Delta s)$, all the goods ordered by the retailer are cleared, and the bank's loan is repaid by it. At this time, the repurchase agreement will not be executed, so the bank's expected return is

$$
\Pi_{B c}=\beta \gamma Q_{c 1} p\left(e^{r_{b}}-e^{r_{f}}\right)
$$

When $x \leq\left(\gamma Q_{c 1} \beta p e^{r_{b}}-\Delta s Q_{c}\right) /(p-\Delta s)$, the supplier will repurchase with repurchase ratio $t$ and repurchase price $w$. If the retailer defaults, the bank's expected return is

$$
\begin{aligned}
E \pi_{B c}^{\varphi_{r}}= & p \int_{0}^{\gamma Q_{c 1}\left(\beta p e^{r_{b}}-\Delta s\right) /(p-\Delta s)} x f(x) d x \\
& +\Delta s \int_{0}^{\left(\gamma Q_{c 1} \beta p e^{\left.r_{b}-\Delta s Q_{c}\right) /(p-\Delta s)}\right.} f(x) d x \\
& -\beta \gamma Q_{c 1} p e^{r_{f}} F\left(\frac{\gamma Q_{c 1} \beta p e^{r_{b}}-\Delta s Q_{c}}{p-\Delta s}\right)
\end{aligned}
$$

According to the previous definition, the probability of retailer's default and nondefault is $\varphi_{r}$ and $1-\varphi_{r}$ respectively, and the bank's expected return is

$$
\begin{aligned}
E \pi_{B c}= & \Pi_{B c}\left(1-F\left(\frac{\gamma Q_{c 1} p \beta e^{r_{b}}-\Delta s Q_{c}}{p-\Delta s}\right)\right) \\
& +\left(1-\varphi_{r}\right) \Pi_{B c} F\left(\frac{\gamma Q_{c 1} p \beta e^{r_{b}}-\Delta s Q_{c}}{p-\Delta s}\right) \\
& +\varphi_{r} \pi_{B c}^{\varphi_{r}} \\
= & \beta \gamma Q_{c 1} p\left(e^{r_{b}}-e^{r_{f}}\right) \\
& -\varphi_{r}(p-\Delta s) \int_{0}^{\left(\gamma Q_{c 1} p \beta e^{r_{b}}-\Delta s Q_{c}\right) /(p-\Delta s)} F(x) d x
\end{aligned}
$$

4.1.2. Expected Return Functions of the Retailer and Supplier. In the centralized supply chain, we assume that the supplier provides goods to the retailer with cost price, and there is no wholesale income. Therefore, the supplier's return is fully from the retailer's revenue sharing. If the retailer defaults, the supplier needs to bear some risk of repurchase guarantees.

In light of studies in Section 3.1.2, considering two situations of nondefault and default by the retailer, the joint expected return of the retailer and supplier in the centralized supply chain is

$$
\begin{aligned}
E \pi_{c}= & \left(1-\varphi_{r}\right)\left[p \min \left(Q_{c}, x\right)-C\right] \\
& +\varphi_{r}\left[p \int_{0}^{\gamma Q_{c 1} \beta p e^{r_{b}} / p} F(x)-t w\left(Q_{c}-x\right)\right] d x
\end{aligned}
$$

From (1) to (5), it is further deduced that

$$
\begin{aligned}
E \pi_{c}= & \left(1-\varphi_{r}\right)\left[Q_{c}(p-c)-\frac{\beta p \gamma B e^{r_{b} *}}{c}\right] \\
& +\varphi_{r}\left[p \int_{0}^{Q_{c}} F(x)-t w\left(Q_{c}-\int_{0}^{Q_{c}} F(x) d x\right)\right]
\end{aligned}
$$

Moreover, with the revenue sharing coefficient $\lambda$ between the supplier and retailer, we can obtain the retailer's expected return in the centralized supply chain:

$$
E \pi_{r c}=(1-\lambda) E \pi_{c}
$$


And the expected return of the supplier is

$$
E \pi_{s c}=\lambda E \pi_{c}
$$

\subsection{Decision-Making Models of Centralized Supply Chain}

4.2.1. The Bank's Decision. For centralized supply chain, the supplier provides a repurchase guarantee. If insufficient market demand leads the retailer to default, the supplier will repurchase the pledged commodities with ratio $t$ and wholesale price $w$, and the remaining commodities will be disposed by the bank at price $s$.

$$
\beta_{c}=\left\{\begin{array}{l}
\frac{(p-\Delta s) F^{-1}\left(\Delta r / \varphi_{r}\right)+Q_{c} \Delta s}{\gamma Q_{c 1} p e^{r_{b}}} \\
\frac{(p-\Delta s) F^{-1}\left(\psi / \varphi_{r}\right)+Q_{c} \Delta s}{\gamma Q_{c 1} p \Delta l}
\end{array}\right.
$$

where $\widehat{\beta}_{c}=\left((p-\Delta s) F^{-1}\left(\Delta r / \varphi_{r}\right)+Q_{c} \Delta s\right) / \gamma Q_{c 1} p e^{r_{b}}, \Delta r=$ $1-e^{r_{f}-r_{b}}, \Delta l=e^{r_{b}}-l$, and $\Delta s=t w+(1-t) s$.

When $F\left(\left(\widehat{\beta}_{c} p \gamma Q_{c 1} \Delta l-Q_{c} \Delta s\right) /(p-\Delta s)\right) \leq \psi / \varphi_{r}$, we have $\partial \beta_{c} / \partial t=(w-\Delta s)\left[Q_{c}-F^{-1}\left(\Delta r / \varphi_{r}\right)\right] / \gamma Q_{c 1} p e^{r_{b}}$. For $F\left(\left(\widehat{\beta}_{c} p \gamma Q_{c 1} \Delta l-Q_{c} \Delta s\right) /(p-\Delta s)\right)>\psi / \varphi_{r}$, we get $\partial \beta_{c} / \partial t=$ $(w-\Delta s)\left[Q_{c}-F^{-1}\left(\psi / \varphi_{r}\right)\right] / \gamma Q_{c 1} p \Delta l$.

The proof process is similar to Theorem 3. Because $w-$ $\Delta s>0, Q_{c}>F^{-1}\left(\Delta r / \varphi_{r}\right), Q_{c}>F^{-1}\left(\psi / \varphi_{r}\right)$ and the other parameters are greater than 0 , it can be deduced that $\partial \widehat{\beta}_{c} / \partial t>$ 0 and $\partial \beta_{c} / \partial t>0$. Consequently, in the centralized supply chain, when other conditions remain unchanged, $\beta_{c}$ is a monotonically increasing function of $t$. The proof is completed.

It suffices to show that, different from decentralized supply chain, the supplier's repurchase strategy can increase the bank's loan pledge ratio as well as the retailer's order quantity in centralized supply chain. For the bank, the supplier's repurchase strategy is equivalent to providing a third-party guarantee for the retailer's pledged loans, thus sharing the bank's credit risk and providing an assurance for reducing the loan pledge ratio. In short, in the centralized supply chain, repurchase guarantees can not only promote the retailer's order quantity, but also increase the loan pledge ratio.

Theorem 5. Under the condition of second ordering and supplier's repurchase guarantee, wholesale price $w$ will affect the bank's decision-making behavior in the centralized supply chain, and loan pledge ratio $\beta_{c}$ is a monotonically increasing function of wholesale price $w$.

Proof. Similar to the proof of Theorem 4, we derive the partial derivative of (33) on $w$ and obtain the following equations according to (1) and (5).

$$
\text { If } F\left(\left(\widehat{\beta}_{c} p \gamma Q_{c 1} \Delta l-Q_{c} \Delta s\right) /(p-\Delta s)\right) \leq \psi / \varphi_{r},
$$

We further discuss the relationship between loan pledge ratio $\beta_{c}$ and repurchase ratio $t$, and there is the following theorem.

Theorem 4. In the centralized supply chain, the bank's loan pledge ratio $\beta_{c}$ is a monotonically increasing function of repurchase ratio t provided by the supplier.

Proof. Similar to the case of decentralized supply chain, we can easily derive the bank's loan pledge ratio $\beta_{c}$ as follows.

there is $\partial \beta_{c} / \partial w=\left((p-2 t w-(1-t) s) F^{-1}\left(\Delta r / \varphi_{r}\right)+2 t w Q_{c}+\right.$ $\left.(1-t) s Q_{c}\right) / \gamma p e^{r_{b}} B$

If $F\left(\left(\widehat{\beta}_{c} p \gamma Q_{c 1} \Delta l-\gamma Q_{c 1} \Delta s\right) /(p-\Delta s)\right)>\psi / \varphi_{r}$, there is $\partial \beta_{c} / \partial w=\left((p-2 t w-(1-t) s) F^{-1}\left(\psi / \varphi_{r}\right)+2 t w Q_{c}+\right.$ $\left.(1-t) s Q_{c}\right) / \gamma p \Delta l B$.

Similar to the proof of Theorem 3, we can easily deduce $\partial \beta_{c} / \partial w>0$. Thus, it suffices to show that the bankdetermined loan pledge ratio $\beta_{c}$ is a monotonically increasing function of wholesale price $w$. The proof is completed.

From Theorems 4 and 5, it can be seen that the bank can control its expected return and risk by controlling loan pledge ratio $\beta_{c}$ and lending rate $r_{b}$, while $\beta_{c}$ is influenced by repurchase ratio $t$ and wholesale price $w$ promised by the supplier, that is, because the supplier's repurchase price for remaining goods is equal to wholesale price $w$ when the loan expires. Therefore, as repurchase ratio $t$ is determined, the higher the wholesale price, the greater the total value of remaining goods when the loan expires. The greater the total value of remaining goods, the more compensation the bank will receive when the retailer defaults, which reduces its risk effectively. Hence, under the established risk control level and expected return, the loan pledge ratio will increase with the increase of wholesale prices.

4.2.2. Decision-Making in a Centralized Supply Chain. In the centralized supply chain, we can think of the retailer and supplier as a whole. The decision-making goal of supply chain is to maximize the overall expected returns of them, satisfying the risk control conditions of the retailer, supplier, and bank, respectively. The decision-making target function of centralized supply chain is

$$
\begin{array}{ll}
\max _{Q>0} & E \pi_{c}(Q) \\
\text { s.t. } & P\left\{\pi_{r c}(Q)<\pi_{r c 0}\right\} \leq \alpha \\
& \text { Loss }<L
\end{array}
$$


TABLE 1: Comparison with the models in other literatures.

\begin{tabular}{|c|c|c|c|c|c|}
\hline $\begin{array}{l}\text { Research on } \\
\text { retailer's twice } \\
\text { ordering in the } \\
\text { supply chain }\end{array}$ & $\begin{array}{l}\text { Using bank as } \\
\text { financier of the } \\
\text { supply chain }\end{array}$ & $\begin{array}{l}\text { Considering the } \\
\text { risk of financier } \\
\text { in the supply } \\
\text { chain }\end{array}$ & $\begin{array}{l}\text { Considering the } \\
\text { pledge of } \\
\text { warehouse } \\
\text { receipts }\end{array}$ & $\begin{array}{c}\text { Using } \\
\text { Stackelberg } \\
\text { game model for } \\
\text { analysis }\end{array}$ & $\begin{array}{l}\text { Comparing and } \\
\text { analyzing the } \\
\text { decentralized } \\
\text { and centralized } \\
\text { supply chains }\end{array}$ \\
\hline$[25]$ & No & No & Yes & No & Yes \\
\hline [26] & Yes & Yes & No & Yes & No \\
\hline [27] & No & Yes & No & No & No \\
\hline [28] & No & No & No & No & No \\
\hline [29] & No & No & No & Yes & Yes \\
\hline Jia et al. (2007) & No & No & No & Yes & Yes \\
\hline $\begin{array}{l}\text { Jian \& Yong } \\
\text { (2013) }\end{array}$ & No & Yes & No & Yes & No \\
\hline [10] & No & No & No & Yes & Yes \\
\hline
\end{tabular}

where the income of centralized supply chain is $E \pi_{c}(Q)=$ $E \pi_{r c}(Q)+E \pi_{s c}(Q)$, and $\pi_{r c 0}$ is the target expected return set by the retailer.

In the centralized supply chain, the retailer and supplier determine the overall revenue through the revenue sharing mechanism. They can coordinate their respective return by adjusting revenue sharing coefficient $\lambda$. At the same time, they can also adjust the repurchase ratio and price to change the bank's lending rate and pledge ratio, which further affects the retailer's order quantity. Moreover, due to the supplier's repurchase guarantee reducing the retailer's default risk, so the bank is willing to lower lending rate $r_{b}$ or increase pledge ratio.

4.3. Comparison with the Models in Other Literature. In the existing studies, there are few literatures analyzing the supply chain from the perspective of the retailer's twice ordering, and they rarely take banks as the financiers of the supply chain for in-depth study ([25, 27-29]; Jia et al., 2007; Jian and Yong, 2013; [10]). Our study differs from Zhao [26], who incorporated the bank's decision into supply chain finance, and considered risk constraints during the study. We conduct the research from the perspective of retailer's warehouse receipt pledge, and the fund of twice ordering is from the pledge financing of the first ordering goods. In this paper, the game of bank versus retailer and retailer versus supplier all belong to the sequential game; one side of the game plays a dominant role. Hence, this paper introduces the Stackelberg game model to analyze. Similar to the research methods of Zhang and Wang [25], Zhang and Pang [29], Jia et al. (2007), and Zhang and Hong [10], this paper also compares the decision-making issues under centralized and decentralized supply chains. Moreover, in the studies of retailer's twice ordering, there are relatively few literatures combining the factors of warehouse receipt pledge and the financier's risk in the supply chain ([25-27]; Jian and Yong, 2013). In order to make the decision models more perfect and close to reality, this paper takes into account several factors such as the bank's decision, risk of participation, and warehouse receipt pledge. The specific comparison between this study and the existing literatures is shown in Table 1.

\section{A Simulation Analysis}

We present in this section a simulation analysis to show how our analysis works under the stated assumptions. We solve the problem with the proposed model in which the price of $p=10$, the wholesale price of $w=5$, the initial capital of $B=1000$, the first-ordering quantity of $Q_{1}=B / w=200$, the optimal proportion of $\gamma=0.8$, the pledge ratio of $\beta=0.5$, the lending rate of $r_{b}=4.35 \%$, the risk-free interest rate of $r_{f}=1.75 \%$, the twice ordering quantity of $Q_{2}=Q_{1} \beta \gamma p / w=160$, the product's disposal price of $s=3$, the cost of $c=4$, and the bankruptcy probability of $\varphi_{r}=10 \%$.

\subsection{Decision Factors of Decentralized Supply Chain}

5.1.1. A Simulation Analysis of the Bank's Expected Return. In light of the previous research, we present a simulation of the relationship between the expected return and bank's decision in the decentralized supply chain in Figure 1. It is apparent that the bank's expected return $E \pi_{B}$ rises as pledge ratio $\beta$ and lending rate $r_{b}$ increase. When $r_{b}$ is greater than riskfree rate $r_{f}$ and $\beta \neq 0$, the bank begins to make profits, its expected return will increase more with the increase of $\beta$ and $r_{b}$. It is because that the increase of $\beta$ makes the retailer's total amount of loans become greater; while lending rate $r_{b}$ is unchanged, the bank's expected return will increase simultaneously.

5.1.2. A Simulation Analysis of the Bank's Expected Loss. We present a simulation of the relationship between the bank's expected loss and credit decision in the decentralized supply chain, as shown in Figure 2. When $\beta$ is in the range of $0 \sim 0.25$, the bank's expected loss gradually increases as $r_{b}$ rises. At this stage, $r_{b}$ and the bank's expected loss show a strict positive correlation. When $\beta$ is in the range of $0.25 \sim 1$, a depression appears in the surface of Figure 2; we called this "U-bottom". Under the "U-bottom", the relationship between $r_{b}$ and the bank's expected loss is negatively related first and then positively correlated. Furthermore, with the increase of $r_{b}$, the expected loss gradually leaves the "U-bottom" and becomes great increase and shows a strict positive correlation. From 


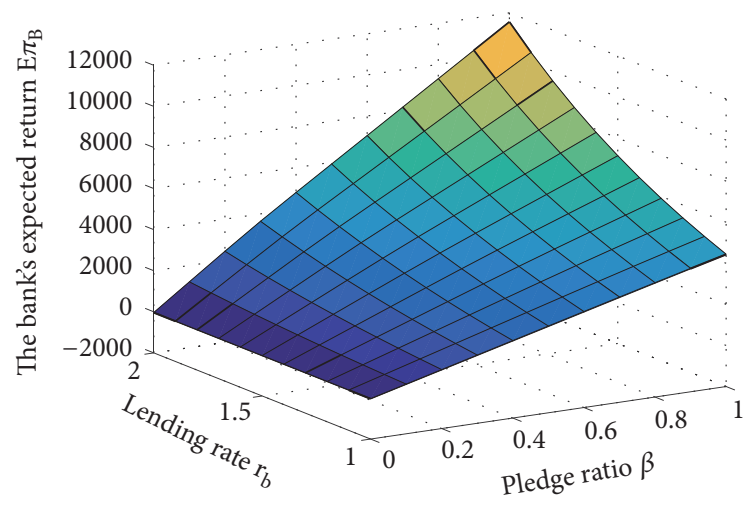

FIGURE 1: The bank's expected return in the decentralized supply chain.

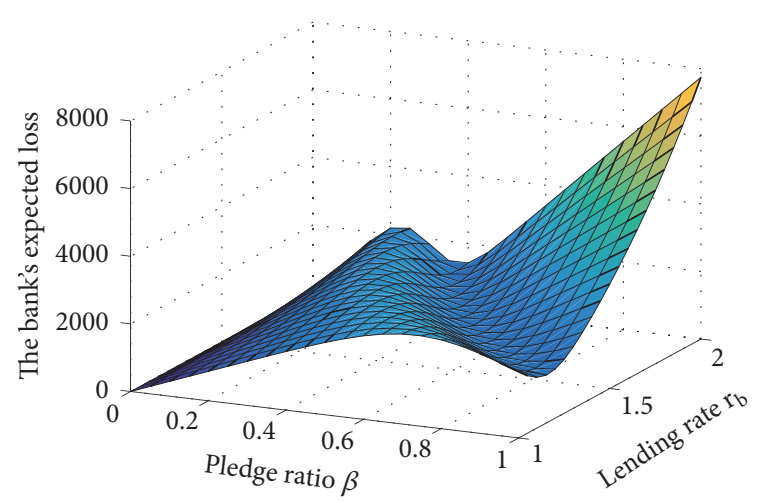

FIGURE 2: The bank's expected loss in the decentralized supply chain.

another dimension, there is a similar relationship between $\beta$ and the bank's expected loss. Therefore, it can be deduced from Figure 2 that the bank's optimal risk decision-making portfolio $\left(r_{b}, \beta\right)$ in the decentralized supply chain should be within the "U-bottom" (without considering the bank's return). It means that this can control the bank's risk in an optimal range by controlling the value of $r_{b}$ and $\beta$. Consequently, the bank's optimal credit decision can be made combining the bank's expected profit Figure 1 with the specific indicators of the downside risk control.

5.1.3. A Simulation Analysis of the Supplier's Expected Return. In the decentralized supply chain, the supplier's expected return function is not directly affected by the bank's credit decision, but only related to the retailer's order decision. According to the previous assumptions, since the cost price $c=4$, the supplier will make profits only when $w>c$. Consequently, when $w \leq 4$ in Figure 3, the supplier's expected return will decrease as the increment of $\beta$; when $w>4$, his expected return will rise as $\beta$ increases. Furthermore, as can be seen from Figure 3, the supplier's return shows an increasing trend with the increase of $w$ as a whole. This is because in the decentralized supply chain, there is no repurchase guarantee and revenue sharing contract between the retailer and the supplier. The supplier's revenue is only related to the wholesale amount and has nothing to do with

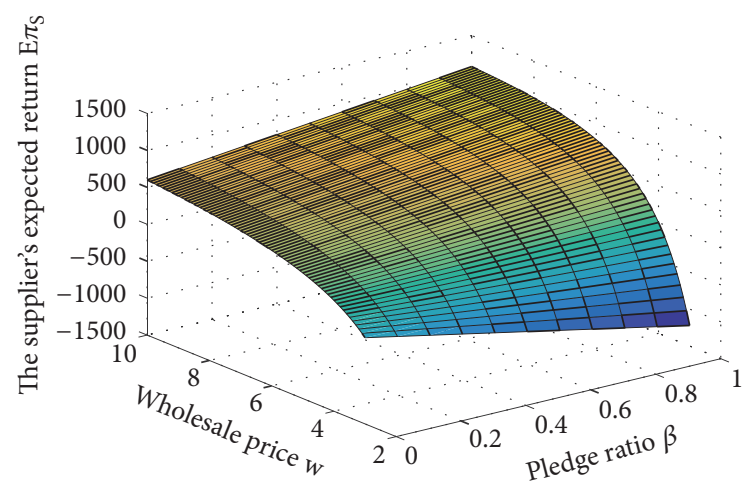

FIGURE 3: The supplier's expected return in the decentralized supply chain.

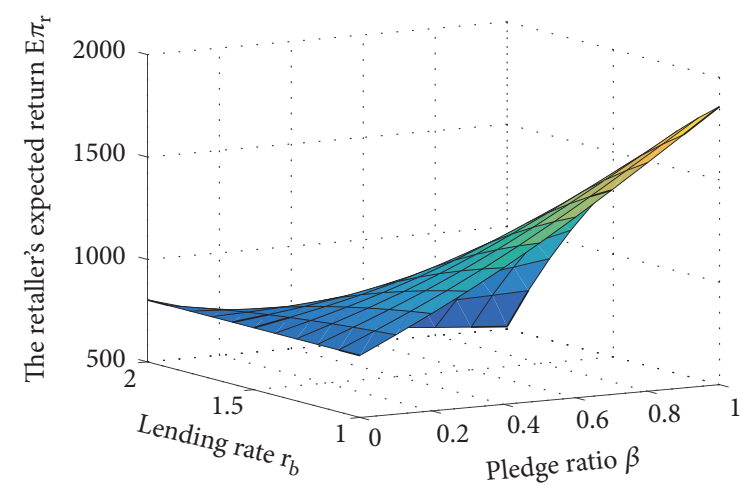

FIGURE 4: The retailer's expected return in the decentralized supply chain.

the bank; hence, the bank's decision-making behavior will not affect the expected return of the supplier.

5.1.4. A Simulation Analysis of the Retailer's Expected Return. In the decentralized supply chain, without repurchase agreement and revenue sharing agreement, the relationship between the retailer and supplier is relatively weak. Therefore, the bargaining capability of the retailer is also weak. Figure 4 shows the retailer's expected return, which reveals that when lending rate $r_{b}$ is fixed and lower than 1.5 , the retailer's return will increase with the growth of pledge ratio; when $r_{b}$ is higher than 1.5, the expected return will increase as the pledge ratio decreases. It is that lower financing cost is beneficial to the retailer for an increase in market share, sales profits, and vice versa. Meanwhile, it shows in Figure 4 that when pledge ratio $\beta$ is fixed, the retailer's return will decrease with the increase of lending rate $r_{b}$, which is consistent with the actual market conditions.

\subsection{Decision Factors of the Centralized Supply Chain}

5.2.1. A Simulation Analysis of the Bank's Expected Return. According to the previous research, the bank's expected return can be obtained under different repurchase ratios in the centralized supply chain. As shown in Figure 5, the change in repurchase ratio $t$ has little impact on the bank's expected 


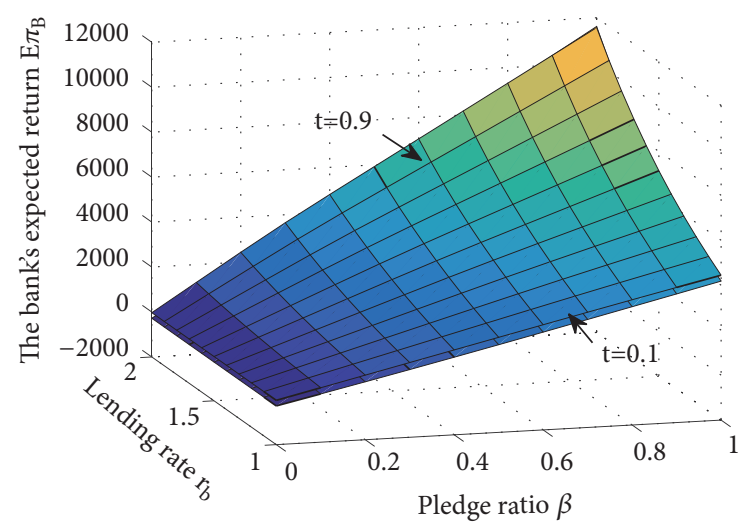

FIGURE 5: The bank's expected return in the centralized supply chain.

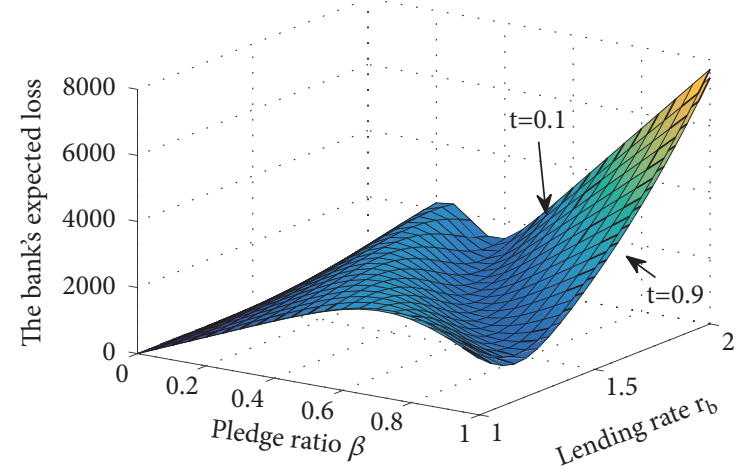

FIgURE 6: The bank's expected loss in the centralized supply chain.

return. We give a simulation analysis of the bank's expected return when repurchase ratio $t=0.1$ and $t=0.9$. When $t=0.1$, the bank's expected return surface is over the surface at $t=0.9$. It indicates that when $\beta$ and $r_{b}$ are fixed, with the increase of $t$, the bank's expected return decreases, but only by a small margin.

5.2.2. A Simulation Analysis of the Bank's Expected Loss. In the centralized supply chain, the bank's expected loss will also be affected by repurchase ratio, as shown in Figure 6.

From Figure 6, it can be inferred that, in the centralized supply chain, the bank's loss risk shows a declining trend for the supplier's repurchase guarantee, and it gradually decreases while repurchase ratio $t$ increases. This is consistent with the underlying reasons for the increase of the bank's expected return with repurchase ratio in Figure 5. If repurchase ratio $t$ increases, the bank will receive relatively more financial compensation after the retailer's bankruptcy, and it will reduce the bank's risk. Similar to the decentralized supply chain, there is a U-shaped depression in Figure 6 for the bank's expected loss, so that the bank's optimal decision should also be located in the region.

5.2.3. A Simulation Analysis of Total Expected Return of Centralized Supply Chain. In the centralized supply chain, since there are repurchase agreement and revenue sharing agreement between the retailer and supplier, we can treat them as a whole and analyze their total revenue as the return

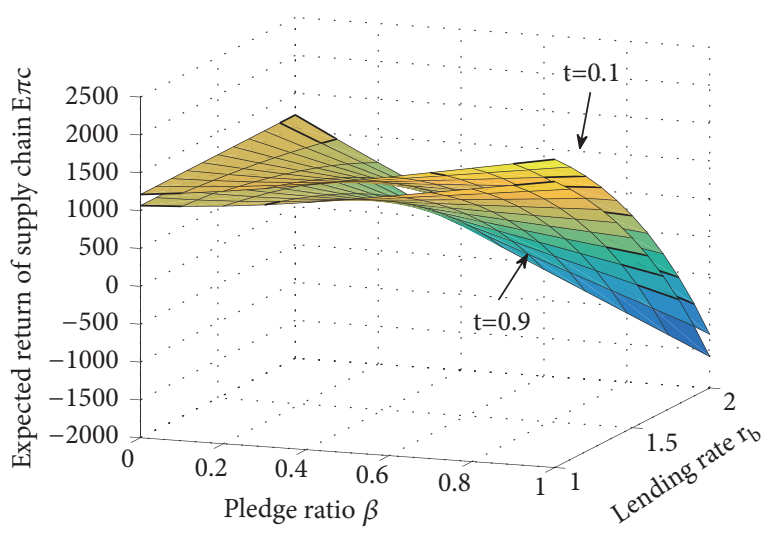

FIGURE 7: The expected return of centralized supply chain.

of supply chain. Furthermore, the repurchase guarantee can correspondingly enhance retailer's bargaining capability; it will actually reduce their total revenue to some extent. For simplicity, we only analyze situations that when repurchase ratio $t=0.1$ and $t=0.9$, as shown in Figure 7 .

In the centralized supply chain, according to the revenue sharing contract, both the retailer and the supplier can perform profit sharing. At this time, the supplier's profit situation is completely different from that in the decentralized supply chain. In the decentralized supply chain, the supplier's return is only positively correlated with sales volume; while in the centralized supply chain, the retailer's unit product revenue $(p-w)$ is much larger than supplier's unit product revenue $(w$ $c)$, so the supplier can obtain sales profit from the retailer by proportion $\lambda$. Consequently, in the centralized supply chain, the supplier's return pattern is similar to the retailer's. With the increase of revenue sharing coefficient $\lambda$, the supplier's return will rise. Moreover, by comparing return of different repurchase ratio $t$ in Figure 7, it can be seen that the increase of $t$ will reduce the total revenue level of supply chain.

5.3. A Simulation Analysis of Supply Chain Decision-Making Process. Different from decentralized supply chain, the supplier will provide a repurchase guarantee agreement to the retailer in the centralized supply chain. If the insufficient market demand leads to the retailer's bankruptcy, the supplier will repurchase goods at agreed repurchase ratio and price. In addition, they also have a revenue sharing agreement. In view of this, the decision-making process of centralized supply chain is more complex than the decentralized one, and it is also in conformity with the actual market. Therefore, here we take the centralized supply chain as an example to carry out a simulation analysis of the decision-making process, which can be divided into three steps.

Step 1 (the bank's decision-making). Firstly, we find out the ranges of pledge ratio $\beta_{c}$ and lending rate $r_{b}$ that meet the bank's downside risk control requirements according to the bank's decision model in Section 4.2. We assume the maximum expected loss that the bank can bear is $L=2000$, as shown in Figure 8 , where the $x$-axis represents $\beta_{c}$, the $y$-axis denotes $r_{b}$, and the $z$-axis indicates the bank's expected loss. 


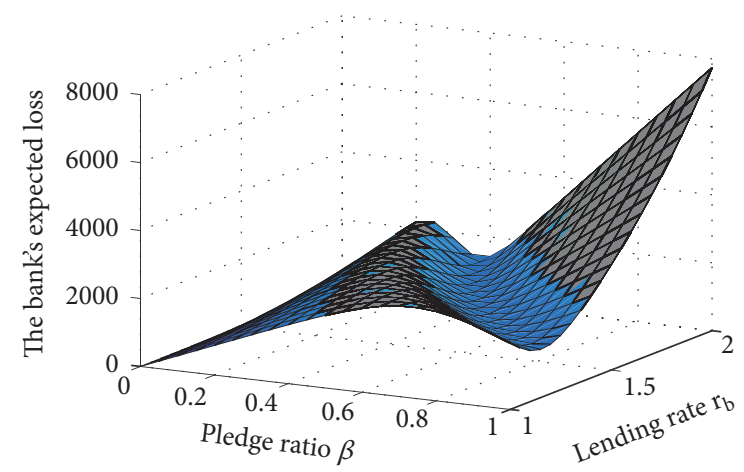

FIGURE 8: The bank's possible decision points in a centralized supply chain.

The dark shaded part in Figure 8 is the part when the bank's expected loss $L>2000$, which needs to be removed, because for this part the bank's expected loss has exceeded the maximum. After eliminating the dark shaded data, we obtain a set of bank's feasible decision points and calculate the bank's expected loss for each decision point (Table 2). Next, we find out all the decision points that meet the condition of downside risk control and get the expected return values for these decision points (Table 3). Furthermore, we finally find out the ideal decision point which maximizes the bank's expected return among these points, that is, $\beta=0.9, r_{b}=1.4$, the expected return is 5852 .

Step 2 (the supply chain's decision-making). Equation (34) shows that the decision-making target of the centralized supply chain is to maximize its return, and the probability of the return less than the preset target return should not be lower than the given confidence level. We substitute $\beta=0.9$ and $r_{b}=1.4$ obtained in Step 1 into the decision-making process and calculate the total expected return $E \pi_{c}$ and corresponding order quantity $Q_{c}$ of supply chain with twice ordering quantity proportion $\gamma$. The results are shown in Table 4. It can be seen that when $\gamma=1, E \pi_{c}$ is the largest, $Q_{c}=560$. In the next step, we will check whether the order quantity satisfies the downside risk control requirement.

Step 3 (test risk requirements). In light of assumptions in this paper, market demand $x$ obeys a normal distribution with the mean of 250 and the variance of 100. In (34), we assume that the centralized supply chain must ensure that its order quantity does not exceed market demand at a $5 \%$ significance level; that is, the order quantity of centralized supply chain should not exceed $Q_{0.95}, Q_{0.95}=\mu-1.64 \sigma=343.6$. As we can see from Table 4 , the twice order quantity proportion $\gamma=1$ maximizing the return of supply chain does not meet the risk requirement. Only $\gamma=0.3$ can satisfy the market demand, where the expected return of supply chain is 1199 and the total order quantity is 308 .

\section{Extended Studies}

In order to simplify the research mechanism, we only considered the fixed retail price in previous sections. However,

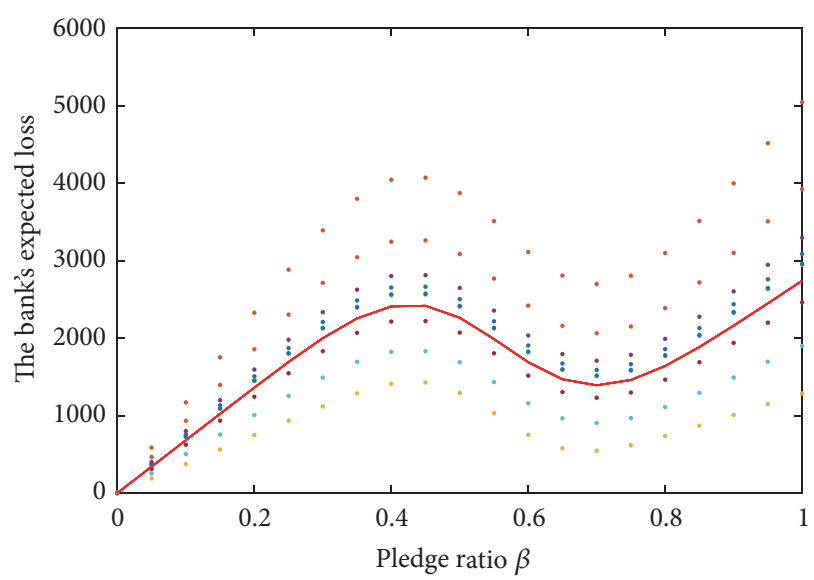

FIGURE 9: The bank's expected loss when the market price randomly fluctuates with $r_{b}=1.45 \%$.

market price in reality is constantly changing. It is necessary to conduct analysis based on actual conditions. In this section, we study the influence of the pledges' price changes on the decision-making behavior in the centralized supply chain.

6.1. The Bank's Expected Loss When the Pledges' Price Changes. In this section, we first simulate and analyze the market's expected loss when market prices change. We assume that lending rate $r_{b}=1.45 \%$ and simulate the bank's loss under different pledge ratios when market price $p$ randomly fluctuates, as shown in Figure 9. The red line denotes the bank's loss when $p=10$. If the downside risk control is adopted, the loss threshold can be kept at around 2500 when $p$ is assumed to be constant. However, if $p$ randomly fluctuates, then the bank's expected loss will easily break through the lower limit. From Figure 9, we know that the point near $\beta=0.7$ is ideal, which is in the "U-shaped" bottom area of the bank's risk loss, and this will make the bank less risky and more profitable. The falls of the pledges' market price not only increase the minimum loss of decision point, but also push up the actual pledge ratio, making the points in the optimal decision area in Figure 6 shift to the upper right and even move out of the optimal decision area. Hence, the bank's expected loss will increase sharply (Figure 9).

6.2. Fluctuation Analysis of Actual Pledge Ratio When the Pledges' Price Changes. In this case, we introduce the cordon mechanism into warehouse receipt pledge financing to measure the fluctuation of actual pledge ratio. When the market price fluctuates, we set a warning line and a close-position line for pledge ratio $\beta$. When price $S_{t}$ of the pledge reaches the threshold $l$ of warning line, the retailer needs to make up the position; that is, it will increase the pledge amount to $l$ or more. When $S_{t}$ reaches the threshold $L$ of close-position line, the supplier will repurchase the pledge, and the bank will handle the remaining pledges on its own; this process is called mandatory close-position.

We assume that the initial market price of the pledge is $S_{0}$, and the financing amount is $K$. At the initial moment, the retailer mortgages the goods to the bank at price $S_{0}$ and 
TABLE 2: The expected loss of the bank's decision points in the centralized supply chain.

(a)

\begin{tabular}{|c|c|c|c|c|c|c|c|c|c|c|c|}
\hline \multirow{2}{*}{$r_{b}$} & \multicolumn{11}{|c|}{$\beta$} \\
\hline & 0 & 0.05 & 0.1 & 0.15 & 0.2 & 0.25 & 0.3 & 0.35 & 0.4 & 0.45 & 0.5 \\
\hline 1 & 0.1307 & 217.6 & 435.1 & 652.5 & 869.7 & 1087 & 1303 & 1517 & 1728 & 1933 & - \\
\hline 1.05 & 0.1307 & 228.7 & 457.3 & 685.9 & 914.3 & 1142 & 1369 & 1593 & 1812 & - & - \\
\hline 1.1 & 0.1307 & 240.5 & 480.8 & 721 & 961 & 1200 & 1438 & 1672 & 1898 & - & - \\
\hline 1.15 & 0.1307 & 252.8 & 505.4 & 758 & 1010 & 1261 & 1510 & 1753 & 1985 & - & - \\
\hline 1.2 & 0.1307 & 265.7 & 531.3 & 796.8 & 1062 & 1325 & 1585 & 1837 & - & - & - \\
\hline 1.25 & 0.1307 & 279.4 & 558.5 & 837.6 & 1116 & 1392 & 1663 & 1922 & - & - & - \\
\hline 1.3 & 0.1307 & 293.7 & 587.2 & 880.4 & 1173 & 1462 & 1744 & - & - & - & - \\
\hline 1.35 & 0.1307 & 308.7 & 617.2 & 925.5 & 1232 & 1535 & 1826 & - & - & - & - \\
\hline 1.4 & 0.1307 & 324.5 & 648.9 & 972.8 & 1295 & 1611 & 1910 & - & - & - & - \\
\hline 1.45 & 0.1307 & 341.2 & 682.1 & 1022 & 1360 & 1689 & 1933 & - & - & - & - \\
\hline 1.5 & 0.1307 & 358.7 & 717 & 1075 & 1429 & 1769 & - & - & - & - & - \\
\hline 1.55 & 0.1307 & 377 & 753.8 & 1129 & 1500 & 1851 & - & - & - & - & 1827 \\
\hline 1.6 & 0.1307 & 396.4 & 792.4 & 1187 & 1574 & 1933 & - & - & - & 1984 & 1632 \\
\hline 1.65 & 0.1307 & 416.7 & 832.9 & 1247 & 1650 & - & - & - & - & 1797 & 1470 \\
\hline 1.7 & 0.1307 & 438 & 875.5 & 1310 & 1729 & - & - & - & 1989 & 1615 & 1369 \\
\hline 1.75 & 0.1307 & 460.5 & 920.3 & 1376 & 1809 & - & - & - & 1813 & 1467 & 1351 \\
\hline 1.8 & 0.1307 & 484.1 & 967.3 & 1445 & - & - & - & - & 1639 & 1382 & 1421 \\
\hline 1.85 & 0.1307 & 508.9 & 1017 & 1516 & - & - & - & 1880 & 1495 & 1378 & 1570 \\
\hline 1.9 & 0.1307 & 534.9 & 1069 & 1590 & - & - & - & 1721 & 1407 & 1458 & 1781 \\
\hline 1.95 & 0.1307 & 562.4 & 1123 & 1666 & - & - & 1999 & 1561 & 1369 & 1613 & - \\
\hline 2 & 0.1307 & 591.2 & 1180 & 1744 & - & - & 1845 & 1454 & 1466 & 1826 & - \\
\hline
\end{tabular}

(b)

\begin{tabular}{|c|c|c|c|c|c|c|c|c|c|c|}
\hline \multirow{2}{*}{$r_{b}$} & \multicolumn{10}{|c|}{$\beta$} \\
\hline & 0.55 & 0.6 & 0.65 & 0.7 & 0.75 & 0.8 & 0.85 & 0.9 & 0.95 & 1 \\
\hline 1 & - & - & - & - & - & - & - & - & 1949 & 1704 \\
\hline 1.05 & - & - & - & - & - & - & - & 1899 & 1649 & 1419 \\
\hline 1.1 & - & - & - & - & - & - & 1870 & 1613 & 1386 & 1214 \\
\hline 1.15 & - & - & - & - & - & 1860 & 1597 & 1370 & 1207 & 1124 \\
\hline 1.2 & - & - & - & - & 1871 & 1600 & 1369 & 1213 & 1144 & 1160 \\
\hline 1.25 & - & - & - & 1901 & 1620 & 1382 & 1226 & 1168 & 1202 & 1307 \\
\hline 1.3 & - & - & 1950 & 1660 & 1408 & 1246 & 1193 & 1240 & 1363 & 1534 \\
\hline 1.35 & - & - & 1719 & 1449 & 1273 & 1216 & 1272 & 1410 & 1598 & 1813 \\
\hline 1.4 & - & 1800 & 1508 & 1307 & 1238 & 1294 & 1444 & 1649 & 1880 & - \\
\hline 1.45 & 1902 & 1588 & 1353 & 1259 & 1308 & 1464 & 1683 & 1931 & - & - \\
\hline 1.5 & 1693 & 1417 & 1283 & 1313 & 1469 & 1699 & 1964 & - & - & - \\
\hline 1.55 & 1507 & 1319 & 1312 & 1458 & 1696 & 1977 & - & - & - & - \\
\hline 1.6 & 1376 & 1312 & 1434 & 1673 & 1968 & - & - & - & - & - \\
\hline 1.65 & 1325 & 1400 & 1630 & 1935 & - & - & - & - & - & - \\
\hline 1.7 & 1366 & 1568 & 1877 & - & - & - & - & - & - & - \\
\hline 1.75 & 1494 & 1795 & - & - & - & - & - & - & - & - \\
\hline 1.8 & 1690 & - & - & - & - & - & - & - & - & - \\
\hline 1.85 & 1934 & - & - & - & - & - & - & - & - & - \\
\hline 1.9 & - & - & - & - & - & - & - & - & - & - \\
\hline 1.95 & - & - & - & - & - & - & - & - & - & - \\
\hline 2 & - & - & - & - & - & - & - & - & - & - \\
\hline
\end{tabular}


TABLE 3: The expected return of the bank's decision points in the centralized supply chain.

\begin{tabular}{|c|c|c|c|c|c|c|c|}
\hline \multirow{2}{*}{$r_{b}$} & \multicolumn{7}{|c|}{$\beta$} \\
\hline & 0.4 & 0.5 & 0.6 & 0.7 & 0.8 & 0.9 & 1 \\
\hline 1 & - & - & - & - & - & - & - \\
\hline 1.1 & - & - & - & - & - & 4398 & 4873 \\
\hline 1.2 & - & - & - & - & 4321 & 4843 & 5358 \\
\hline 1.3 & - & - & - & 4181 & 4756 & 5324 & 5889 \\
\hline 1.4 & - & - & 3965 & 4601 & 5227 & 5852 & - \\
\hline 1.5 & - & - & 4365 & 5057 & 5764 & - & - \\
\hline 1.6 & - & 4030 & 4798 & 5559 & - & - & - \\
\hline 1.7 & 3567 & 4432 & 5273 & - & - & - & - \\
\hline 1.8 & 3938 & 4871 & - & - & - & - & - \\
\hline 1.9 & 4330 & 5355 & - & - & - & - & - \\
\hline 2 & 4578 & - & - & - & - & - & - \\
\hline
\end{tabular}

TABLE 4: The retailer's expected return of twice ordering decisions in the centralized supply chain.

\begin{tabular}{lcccccccccc}
\hline$\gamma$ & 0.1 & 0.2 & 0.3 & 0.4 & 0.5 & 0.6 & 0.7 & 0.8 & 0.9 & 1.0 \\
\hline$E \pi_{c}$ & 1118 & 1137 & 1166 & 1199 & 1235 & 1270 & 1306 & 1342 & 1377 & 1413 \\
$Q_{c}$ & 236 & 272 & 308 & 344 & 380 & 416 & 452 & 488 & 524 & 560 \\
\hline
\end{tabular}

raises fund $K$. If the market price makes the actual pledge ratio hit the warning line, $S_{t} \leq l$, then the retailer needs to make up the position; if the market price continues to fall and reach the close-position line, $S_{t} \leq L$, then the retailer will be required to close the position directly, and the bank will have the right to sell the remaining pledged goods at disposal price $s$; if the market price does not reach the warning line and the close-position line before the loan expires, it is normal. Moreover, we assume that the bank's actual pledge ratio is $\omega$, the nominal pledge ratio is $\beta=K / S_{0}$. The warning line and the close-position line for the price of pledged goods can be transformed into the lines of actual pledge ratio. When actual pledge ratio $\omega=K / S_{t}$ and $\omega \geq 1 / l$, the warning line is touched and the pledged goods needs to be replenished; when $\omega=K / S_{t} \geq 1 / L$, the close-position line is hit; it is going into mandatory liquidation.

Let us assume that $\beta=K / S_{0}=70 \%$; the actual pledge ratio is $K / S_{t}$, where $S_{0}=2777$ and $K=1943.9$, so that $\omega=0.7$. Referring to the method of stock pledge repurchasing, we set the warning line $l$ as $135 \%$, the close-position line $L$ as $120 \%$, and select the daily spot price of screw-thread steel HRB400 $20 \mathrm{~mm}$ in Chinese commodity trading market in 2015 as a research sample, and we present the fluctuation of actual pledge ratio $\omega$ in Figure 10.

It is easy to see from Figure 10 that the volatility of actual pledge ratio $\omega$ is dramatic, which shows an upward trend. When $\omega$ exceeds 1 , the bank's risk is relatively high. After May 7, 2015, $\omega$ even exceeded 75\%, far beyond the warning line set in this paper. In the 249 daily data items for 2015, there were 208 data items on the actual pledge ratio breaking through the warning line and 94 data items passing through the closeposition line (Table 5). It obviously shows that, in the short term, the price of screw-thread steel fluctuates considerably,

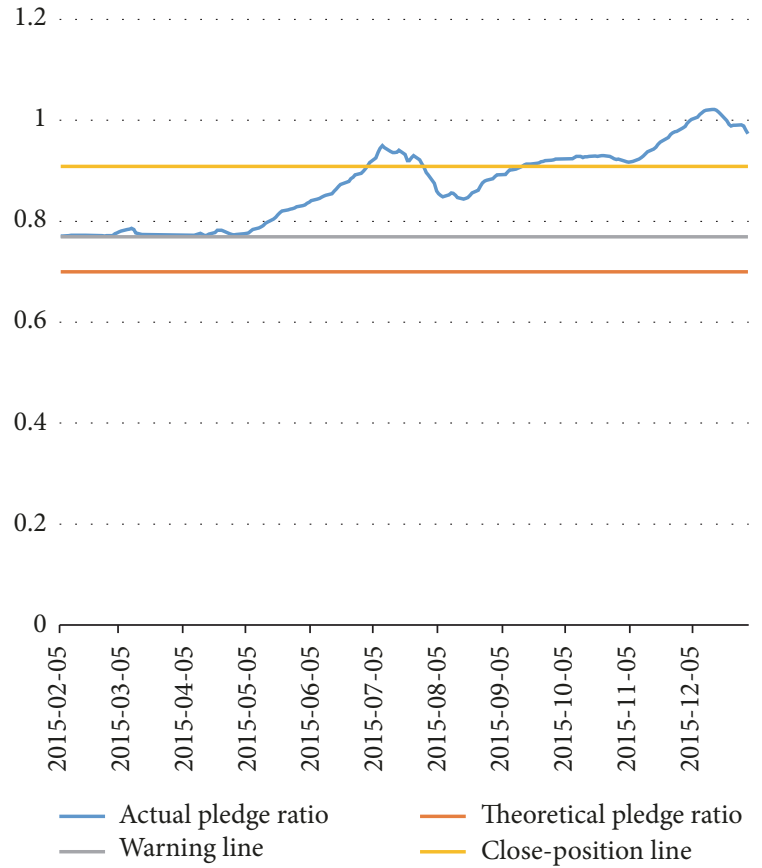

FIGURE 10: The fluctuation of actual pledge ratio of the screw-thread steel in 2015.

so that the fluctuation of $\omega$ repeatedly exceeds the warning line and close-position line. Since the given pledge rate does not respond well to the risks posed by the price volatility of the pledge, hence, in practice, we can combine the warning mechanism and introduce VaR to set the dynamic pledge rate for it, once the fluctuation of market price causes the actual 
TABLE 5: Simulated breakdown frequency of the screw-thread steel in 2015.

\begin{tabular}{lccccc}
\hline Target line & Breakdown condition & 3 months & 6 months & 9 months & 12 months \\
\hline \multirow{2}{*}{$l=135 \%$} & Breakdown frequency $f$ & $10.04 \%$ & $32.53 \%$ & $58.63 \%$ & $83.53 \%$ \\
& Breakdown number N & 25 & 0 & 0 & 146 \\
$\mathrm{~L}=120 \%$ & Breakdown frequency $f$ & 0 & 0 & $12.45 \%$ & $37.75 \%$ \\
& Breakdown number N & 0 & 31 & 94 \\
\hline
\end{tabular}

pledge ratio to hit the warning line, the bank can dynamically adjust the actual pledge ratio by increasing the number of pledged goods to avoid risk.

\section{Conclusion}

This paper studies supply chain decisions making between the retailer, supplier, and bank based on warehouse receipt pledge and risk consideration under twice ordering mode. The decentralized supply chain and centralized supply chain are divided by whether the supplier provides repurchase guarantees and whether the retailer offers revenue sharing. We develop a Stackelberg game model to analyze the influential mechanism among various actors and use the method of downside risk control to discuss the bank's expected loss and the optimal loan pledge ratio. We find that either for decentralized or centralized supply chain, the retailer's optimal order quantity and the optimal proportion that the number of goods pledged in twice ordering accounts for the number of first-ordering goods are all unique. Furthermore, the bank's loan pledge ratio is a monotonically increasing function of disposal value of the unit remaining commodity. However, in the centralized supply chain, the bank's loan pledge ratio is a monotonically increasing function of repurchase ratio and wholesale price provided by the supplier, respectively.

Moreover, we conduct a simulation research and find that (i) in the decentralized supply chain, the bank's expected return will increase as the pledge ratio and lending rate increase, and the bank's risk can be managed in an "optimal" interval by controlling both the lending rate and pledge ratio; (ii) in the decentralized supply chain, the supplier's return mainly comes from the wholesale revenue, which is positively related to sales volume and wholesale price; in the centralized supply chain, it is mainly from the retailer's revenue sharing; (iii) in the decentralized supply chain, when the lending rate remains unchanged, the reduction of pledge ratio to a certain degree will result in a rise of the retailer's return; (iv) in the centralized supply chain, the increase of repurchase ratio will cause the decline of the bank's expected return, but the impact is small.

\section{Data Availability}

The data used to support the findings of this study are available from the corresponding author upon request.

\section{Conflicts of Interest}

The authors declare no conflicts of interest.

\section{Acknowledgments}

This work was supported by the National Natural Science Foundation of China, under Grant no. 71171155; Xi'an Social Sciences Planning Fund major projects, under Grant no. 17J92; and XAUT Science and Technology Innovation Program, under Grant [2016CX009].

\section{References}

[1] J. A. Buzacott and R. Q. Zhang, "Inventory management with asset-based financing," Management Science, vol. 50, no. 9, pp. 1274-1292, 2004.

[2] M. Dada and Q. Hu, "Financing newsvendor inventory," Operations Research Letters, vol. 36, no. 5, pp. 569-573, 2008.

[3] M. R. Fellenz, C. Augustenborg, and M. Brady, "Requirements for an Evolving Model of Supply Chain Finance: A Technology and Service Providers Perspective," Communications of the Ibima, vol. 10, no. 29, pp. 227-235, 2009.

[4] R. Caldentey and M. B. Haugh, "Supply contracts with financial hedging," Operations Research, vol. 57, no. 1, pp. 47-65, 2009.

[5] G. Lai, L. G. Debo, and K. Sycara, "Sharing inventory risk in supply chain: the implication of financial constraint," Omega , vol. 37, no. 4, pp. 811-825, 2009.

[6] Z. Meng and H. G. Hui, "Optimal system design of supply chain finance based on game analysis," in Proceedings of the 2011 International Conference on E-Business and E-Government (ICEE), pp. 1-4, Shanghai, China, May 2011.

[7] X. Bi, X. Dong, and Y.-T. Liu, "Supply chain finance credit risk evaluation based on trapezoid fuzzy number," in Proceedings of the International Asia Conference on Industrial Engineering and Management Innovation: Core Areas of Industrial Engineering, IEMI 2012, pp. 1467-1475, China, August 2012.

[8] J. Liu and Y. He, "Coordinating a supply chain with risk-averse agents under demand and consumer returns uncertainty," Mathematical Problems in Engineering, vol. 2013, Article ID 289572, 10 pages, 2013.

[9] D. A. Wuttke, C. Blome, H. Sebastian Heese, and M. Protopappa-Sieke, "Supply chain finance: Optimal introduction and adoption decisions," International Journal of Production Economics, vol. 178, pp. 72-81, 2016.

[10] H. Zhang and D. Hong, "Supplier's Joint Investments in Cost Reduction and Quality Improvement in a Decentralized Supply Chain," Mathematical Problems in Engineering, vol. 2017, Article ID 4391475, 10 pages, 2017.

[11] E. Hofmann, U. M. Strewe, and N. Bosia, "Background I-What Is Buyer-Led Supply Chain Finance?" in Supply Chain Finance and Blockchain Technology, SpringerBriefs in Finance, pp. 7-23, Springer International Publishing, Cham, 2018.

[12] L. Fang, Y. Xia, and Y. Yang, "Research on Equilibrium of Supply Chain Finance Decision with Retailer's Sale Effort Level," 
Systems Engineering-Theory Practice, vol. 38, no. 1, pp. 135-144, 2018.

[13] R. Pellegrino, N. Costantino, and D. Tauro, "Supply Chain Finance: A supply chain-oriented perspective to mitigate commodity risk and pricing volatility," Journal of Purchasing and Supply Management, 2018.

[14] E. Jokivuolle and S. Peura, "Incorporating collateral value uncertainty in loss given default estimates and loan-to-value ratios," European Financial Management, vol. 9, no. 3, pp. 299314, 2003.

[15] F. González, D. Cossin, and Z. Huang, "A Framework for Collateral Risk Control Determination," Fame Research Paper, 2003.

[16] Y. X. Wang, X. F. Yin, X. G. Zhao et al., “The Research on warehouse receipt pledge for Small and Medium Enterprises," Logistics Engineering \& Management, vol. 31, no. 1, pp. 35-36, 2009.

[17] X. L. Liu, "Research on the Practice of Warehouse Receipts Pledging in Logistics Enterprises," Journal of Nanning Polytechnic, vol. 15, no. 1, pp. 82-84, 2010.

[18] Y. U. Hui and X. P. Zhen, "Loan-to-Value Ratios Model of Pledge by Warehouse Receipts for Small and Medium Enterprises," Chinese Journal of Management Science, vol. 18, no. 6, pp. 104$112,2010$.

[19] G. H. Liu, Third Party Logistics Warehouse Receipt Pledged Financing and Risk Analysis. Logistics Sci-Tech, vol. 6, 56-58, 6, 2012.

[20] S. L. Tang, X. J. Chu, and W. J. Li, "Study on Choosing of Warehouse Receipt Pledge Based on Value at Risk Model," Logistics Engineering \& Management, vol. 34, no. 3, pp. 37-40, 2012.

[21] . Siddayya, V. S. Reddy, S. K. Kammar, and C. Patil, "An Economic Analysis on Warehouse Receipts in Hyderabad-Karnataka Region: A Protective Measure Against Distress Sale of Agriculture Produce," Indian Journal of Economics and Development, vol. 12, no. 1a, p. 265, 2016.

[22] X. Liu, "Study of Risk Management on Pledge of Warehouse Receipts of Logistics Companies," in in Static Mode. Logistics Engineering Management, vol. 37, 07 edition, 2015, pp. 56-57+55.

[23] Y. Luo, Z. Y. Chen, and C. X. Chen, "Robust Optimization on Warehouse Space Allocation of Pledge in Supply Chain Financing," Journal of Railway Science Engineering, vol. 13, no. 02, pp. 394-400, 2016.

[24] Z. Wang, J. Zhang, D. Li, and H. Yin, "Non-standard warehouse receipt pledge credit business process modeling and analysis," in Proceedings of the 2016 5th International Conference on Computer Science and Network Technology (ICCSNT), pp. 3639, Changchun, China, December 2016.

[25] X. J. Zhang and Y. Wang, "Decision-Making and Coordination with Retailer Warehouse Receipts Financing for Second Ordering Mode," Journal of Systems Engineering, vol. 30, no. 5, pp. 671681, 2015.

[26] D. L. Zhao, Research on the Ordering and Financing Decisions of Capital-Constrained Newsvendor under Two Ordering Opportunities, University of Science and Technology of China, 2016.

[27] J.-P. Wang, D.-Q. Yao, and Z.-L. Yang, "Decision making model of supply chain based on risk-averse retailer's second order at end of sales season," Kongzhi yu Juece/Control and Decision, vol. 31, no. 10, pp. 1811-1816, 2016.

[28] Y. W. Zhou and S. D. Wang, "Supply Chain Coordination for Newsvendor-Type Products with Two Ordering Opportunities," in Supply Chain Coordination under Uncertainty, Springer, Berlin Heidelberg, 2011.
[29] S. Zhang, H. Pang, and G. An, "Study of Supply Chain Coordination with Revenue-Sharing Contract under Twice Ordering Policy," Journal of Convergence Information Technology, vol. 8, no. 7, pp. 1-7, 2013. 


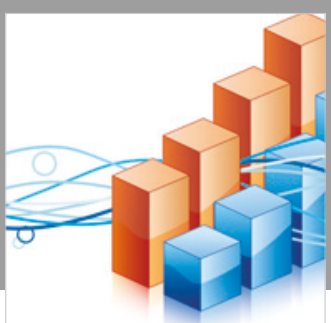

Advances in

Operations Research

\section{-n-m}
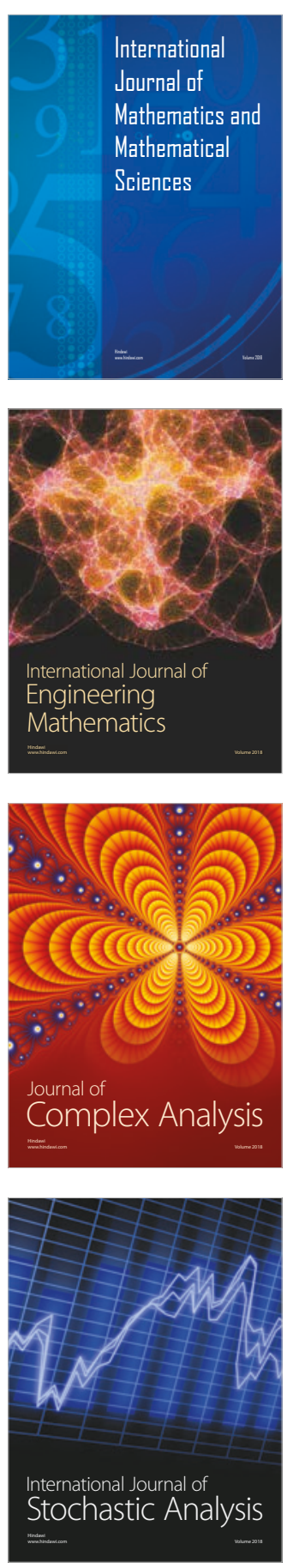
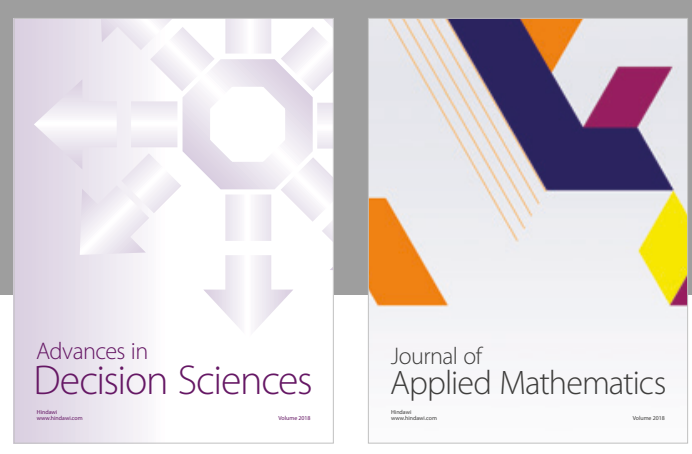

Journal of

Applied Mathematics
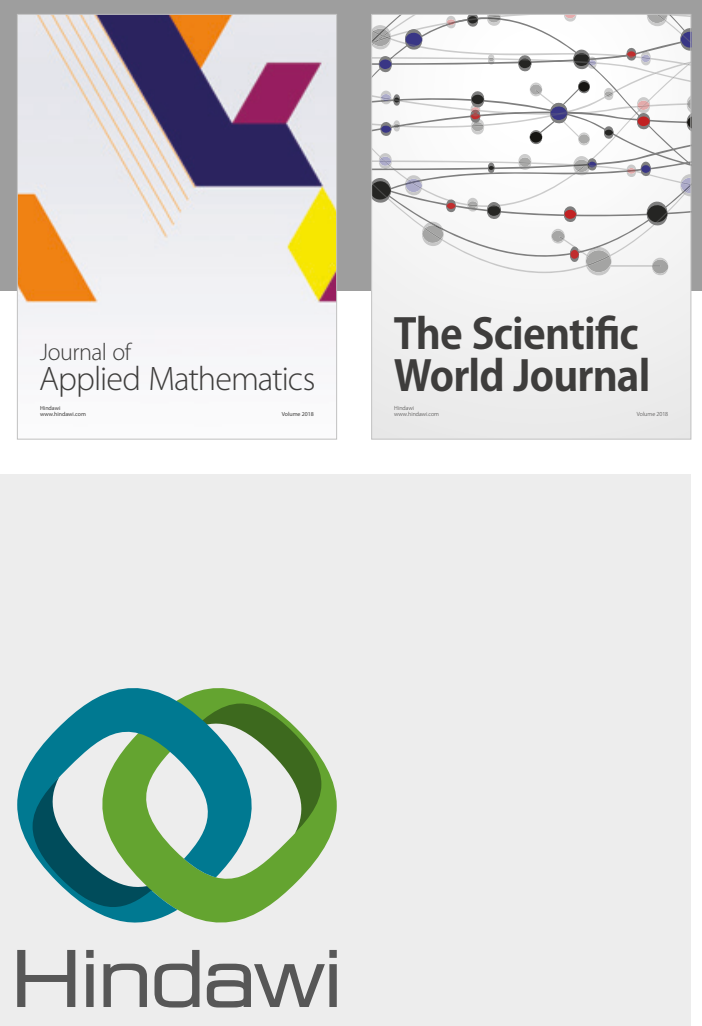

Submit your manuscripts at

www.hindawi.com

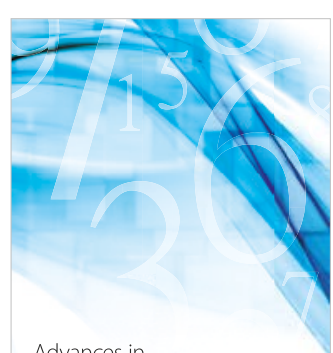

Advances in
Numerical Analysis
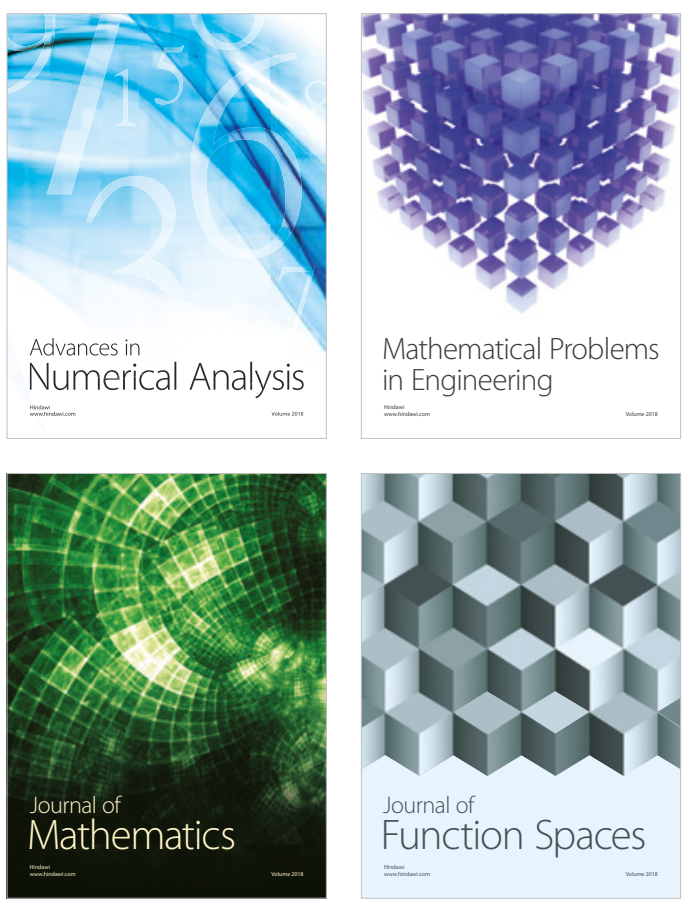

Mathematical Problems in Engineering

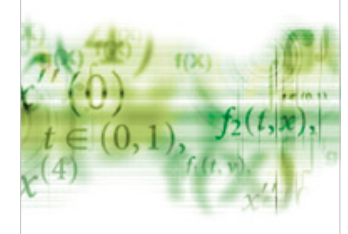

International Journal of

Differential Equations

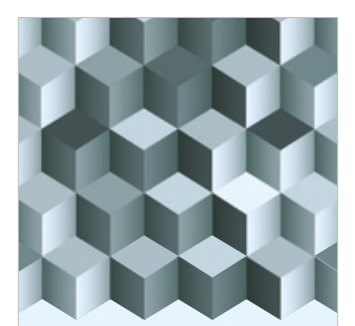

Journal of

Function Spaces

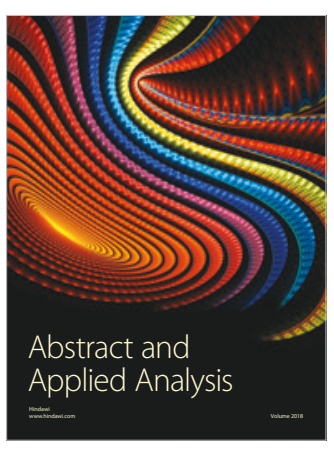

The Scientific

World Journal

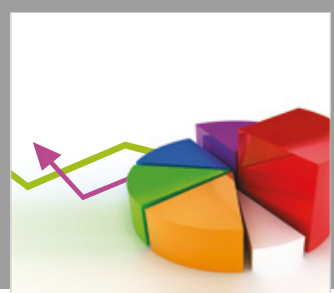

Journal of

Probability and Statistics
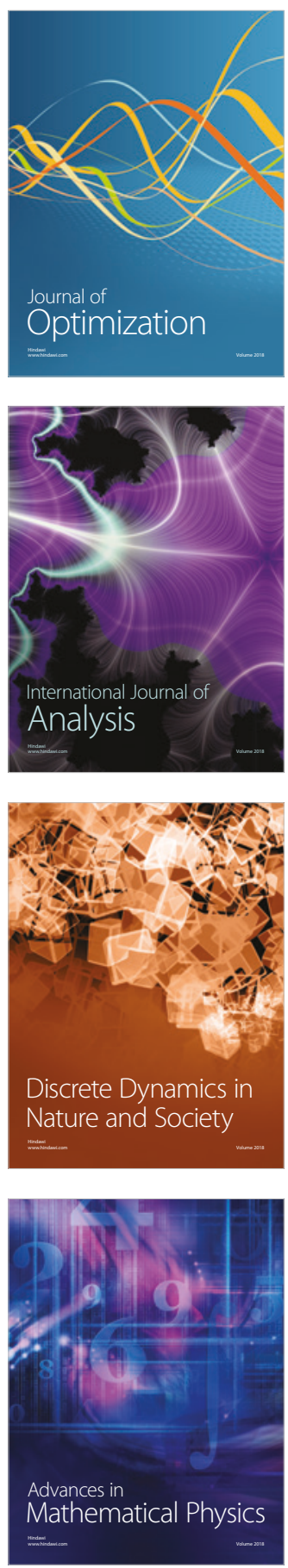